\title{
The Micellar Sink
}

\section{A QUANTITATIVE ASSESSMENT OF THE ASSOCIATION OF ORGANIC ANIONS WITH MIXED MICELLES}

\section{AND OTHER MACROMOLECULAR AGGREGATES IN RAT BILE}

\author{
BRUCE F. SCHARSCHMIDT and RUd SCHMID, Department of Medicine and \\ Liver Center, University of California, San Francisco, San Francisco, \\ California 94143
}

A B S TRACT Although the importance of mixed micelles in the solubilization and biliary excretion of lipids is established, little is known about a possible role of mixed micelles in the excretion of other biliary solutes. Ultrafiltration and ultracentrifugation techniques were used to investigate the interaction between substances that are excreted in bile and biliary mixed micelles. Substances (urea, erythritol, sucrose) excreted in bile at concentrations equal to, or less than, that in plasma did not show an association with mixed micelles, whereas substances (indocyanine green, iopanoic acid, rose bengal, unconjugated and conjugated sulfobromophthalein, and conjugated bilirubin) excreted in bile at high concentration relative to plasma did. The percentage of these latter substances in bile associated with micelles varied from 26 to $93 \%$ and was relatively independent of concentration. In addition to their association with mixed micelles, these test solutes formed self-aggregates that were stabilized primarily by ionic bonds, and only a small percentage (range $=0-5 \%$ ) of these solutes were present in bile in the form of monomer or complexes small enough to pass a 5,000-mol wt membrane.

These findings offer a possible explanation for the increase in sulfobromophthalein, bilirubin, and indocyanine green maximal biliary excretory rate produced by bile salt infusion, and suggest that the concentrative transport into bile of endogenous compounds and xenobiotics may result from their incorpo-

This work was presented in part at the American Gastroenterological Association Meeting, Toronto, Canada in May, 1977 and has previously been published in abstract form. Gastroenterology. 72: A-159/1182.

Dr. Scharschmidt is a recipient of Research Career Development Award 1 KO4 AM-00323 from the National Institute of Arthritis, Metabolism, and Digestive Diseases.

Received for publication 4 November 1977 and in revised form 10 July 1978. ration into mixed micelles and other macromolecular complexes.

\section{INTRODUCTION}

A variety of drugs and organic anions such as sulfobromophthalein (BSP), ${ }^{1}$ indocyanine green (ICG), and conjugated bilirubin (cBR) are excreted primarily by the liver. Because the concentration of these substances in bile exceeds that in plasma and liver by up to two orders of magnitude (1-6), their excretion across the canalicular membrane is generally considered to involve an energy-requiring, concentrative transport process (7-11). However, the concentrative (active) nature of this transport process may be more apparent than real in that it may reflect to a large extent physical association of these substances with mixed micelles. Because molecules that are physically associated with micelles or other macromolecular complexes in bile are osmotically inactive, micelles could function as a "sink" for excreted anions by decreasing their effective concentration in bile.

The following evidence is consistent with this hypothesis. (a) Taurocholate infusion, which increases the biliary output of mixed micelles, increases the maximal biliary excretory rate $\left(T_{m}\right)$ for $\operatorname{BSP}(9,12,13)$,

\footnotetext{
${ }^{1}$ Abbreviations used in this paper: BR, unconjugated bilirubin; BSP, unconjugated sulfobromophthalein; cBR, conjugated bilirubin; $\mathrm{cBSP}$, conjugated sulfobromophthalein; CLMM, $\left[{ }^{14} \mathrm{C}\right]-$ or $\left[{ }^{3} \mathrm{H}\right]$ cholesterol-labeled mixed micelles; ICG, indocyanine green; $r$, membrane rejection coefficient; $R$, percent membrane retention $(r \times 100) ; \mathbf{R}^{\prime},\left(\mathbf{R}_{\mathrm{S}} / \mathbf{R}_{\mathrm{CLMM}}\right) \times 100$ during PM10 ultrafiltration (also a measure of the percentage of test solute in bile associated with mixed micelles); $\mathbf{R}_{\text {CLMM }}$ retention of CLMM; $\mathbf{R}_{\mathbf{S}}$, retention of test solute; $\mathrm{S}$, bile electrolyte solution having an electrolyte composition, $\mathrm{pH}$, and osmolality similar to bile; $T_{m}$, maximal biliary excretory rate in milligrams per minute per kilogram of body weight.
} 
ICG (14), and cBR (15). (b) SC-2644 and theophylline, which increase canalicular bile flow without increasing bile salt output, fail to increase the $T_{m}$ for $\operatorname{BSP}(12,16)$. (c) Secretion of cBR by cultured hepatocytes is markedly enhanced by the presence of taurocholate or mixed bile salt micelles in the medium (17). (d) Ultracentrifugation and gel chromatography of artificial solutions or bile suggest a physical association between $\mathrm{BSP}$ and taurocholate (18) and between $\mathrm{CBR}$ and mixed micelles or some other macromolecular complex in bile (19-22).

Although several investigators have considered the possibility of a physical association between organic anions and mixed micelles (14-18, 23-27) and some supportive evidence for this exists $(18-22,26,27)$, this important hypothesis has never been quantitatively explored.

In this report we demonstrate by two independent techniques that a variety of organic anions associate with biliary mixed micelles and that many of these same compounds also form aggregates by ionic interaction in aqueous solution. Association with mixed micelles and possibly also self-aggregation of these compounds may serve to reduce their relative concentration in the aqueous phase of bile and thereby account for their apparent concentrative transport from liver into bile.

\section{METHODS}

Test substances. Unconjugated bilirubin (BR) (Sigma Chemical Co., St. Louis, Mo.), phenol red (Sigma Chemical Co.), BSP (Sigma Chemical Co.), sodium cholate (Sigma Chemical Co.), cholesterol (Sigma Chemical Co.), erythritol (Sigma Chemical Co.), ICG (Hynson, Westcott and Dunning, Inc., Baltimore, Md.), Evans blue ( J. T. Baker Chemical Co., Fairlawn, N. J.), egg lecithin (Schwarz/Mann Div., Becton, Dickinson \& Co., Orangeburg, N. Y.), urea (Mallinckrodt, Inc., St. Louis, Mo.), sucrose (Mallinckrodt, Inc.), taurine (Calbiochem, San Diego, Calif.), sodium taurocholate (Calbiochem), monoethyl- $\left[{ }^{3} \mathrm{H}\right]$ diethylstilbesterol (Amersham/ Searle Corp., Arlington Heights, Ill.), [ $\left.{ }^{14} \mathrm{C}\right]$ urea (Amersham/ Searle Corp.), $\left[{ }^{14} \mathrm{C}\right]$ erythritol (Amersham/Searle Corp.), $\left[1,2-{ }^{3} \mathrm{H}\right](\mathrm{N})$ testosterone (New England Nuclear, Boston, Mass.), $\left[{ }^{14} \mathrm{C}\right]$ lecithin (New England Nuclear), and $\left[{ }^{3} \mathrm{H}\right]-$ and $\left[{ }^{14} \mathrm{C}\right]$-cholesterol (New England Nuclear) were used directly as supplied by the manufacturer. $\mathrm{cBR}$ was prepared as described previously (28) and consisted of a mixture of mono(70\%) and diconjugates (30\%). Glutathione-conjugated BSP (cBSP) was prepared as described by Whelan et al. (29). Analysis of this preparation by paper chromatography (29) indicated that $<0.5 \%$ of the BSP present was unconjugated. Iopanoic acid was solubilized from Telepaque tablets (Winthrop Laboratories, Sterling Drug Co., New York) in Dr. Henry Goldberg's laboratory at the University of California, San Francisco, San Francisco, Calif. and an electrolyte solution (S) similar to an ultrafiltrate of rat bile in its composition ( $\mathrm{Na}$ $=125 \mathrm{meq} / \mathrm{liter}, \mathrm{Cl}=105 \mathrm{meq} / \mathrm{liter}, \mathrm{K}=5 \mathrm{meq} / \mathrm{liter}$, and $\mathrm{HCO}_{3}=25 \mathrm{meq} / \mathrm{liter}$ ) was prepared. The aqueous solutions of test solute used in ultrafiltration and ultracentrifugation studies were prepared as follows. Crystalline BR was dissolved with heating and stirring in a $\mathrm{NaCl} / \mathrm{Na}_{2} \mathrm{CO}_{3}$ solution $(5.2 \mathrm{~g} /$ liter of each) and aliquots of this solution were added to distilled water, 0.1 and $5.0 \mathrm{M} \mathrm{NaCl}, 5 \mathrm{M}$ urea, Tris buffer, or $\mathrm{S}$. The remaining test solutes were dissolved directly in the appropriate solution in a concentration of $0.0001-10 \mathrm{mM}$. Except where specifically indicated otherwise, the $\mathrm{pH}$ of these solutions was adjusted to 7.6-8.0 with $0.1 \mathrm{~N} \mathrm{HCl}$ or $\mathrm{NaOH}$.

Analytical techniques. Evans blue, phenol red, rose bengal, BSP, cBSP, and ICG concentrations in bile or other solutions were quantitated spectrophotometrically by comparing their optical densities at their respective absorption maxima with standard curves prepared by dissolving weighed amounts of dye in bile or the appropriate reference solution. BSP, cBSP, and phenol red solutions were alkalinized with $0.1 \mathrm{~N} \mathrm{NaOH}$ to $\mathrm{pH} 10$ before analysis. Bilirubin concentrations were determined by the method of Malloy and Evelyn (30) and iopanoic acid concentrations were determined by fluorescent excitation analysis (31). Radioactivity was measured by liquid scintillation counting (Beckman model LS250, Beckman Instruments, Inc., Fullerton, Calif.) with external or internal standardization for quench correction. For determination of total bile salt concentration, the hydroxysteroid dehydrogenase assay of Talalay (32) as modified by Admirand and Small (33) was used. Individual free and conjugated bile salts were separated by thin layer chromatography (34). After scraping the individual bands, bile salts were eluted with methanol and quantitated with the hydroxysteroid dehydrogenase assay $(32,33)$. Total phospholipids were measured by the method of Bartlett (35), and cholesterol was quantitated by gas liquid chromatography. BSP and cBSP in bile were separated and quantitated by paper chromatography (29).

Animal studies. Simonson Sprague-Dawley rats of 290 $350 \mathrm{~g}$ weight on an ad libitum diet were used in all studies. Jugular (polyethylene 10, Clay-Adams Div., Becton, Dickinson \& Co., Parsippany, N. J.) and biliary (polyethylene 90) cannulas were inserted under light ether anesthesia and the animals were restrained. While the animals were infused continuously at $1 \mathrm{ml} / \mathrm{h}$ per $100 \mathrm{~g}$ with an aqueous solution containing $30 \mathrm{mM}$ sodium cholate, $1.9 \mathrm{mM}$ egg lecithin, 0.166 $\mathrm{mM}$ cholesterol, and $30 \mathrm{mM}$ taurine, bile was collected on ice, in the dark, and then frozen. After 2 liters of bile had been collected from $\cong 50$ rats, the bile was thawed, pooled, and refrozen at $-20^{\circ} \mathrm{C}$ in $16-\mathrm{ml}$ aliquots that were used later for the gel filtration, ultrafiltration, and ultracentrifugation studies described below. Some animals were also given an i.v. bolus or continuous infusion $(1 \mathrm{ml} / \mathrm{h}$ per $100 \mathrm{~g}$ ) of isotonic $\mathrm{NaCl}$ containing $\left[{ }^{3} \mathrm{H}\right]$ diphenylhydantoin, $\left[{ }^{3} \mathrm{H}\right]$ testosterone, $\left[{ }^{3} \mathrm{H}\right]-$ diethylstilbesterol, BSP, ICG, BR, rose bengal, or Evans blue in addition to the above solution and bile was collected for analysis in separate experiments. Body temperature was maintained at $37^{\circ} \mathrm{C}$ with an infrared lamp.

Radiolabeling of mixed micelles in vitro. $16 \mathrm{ml}$ of bile in a test tube was overlayered with 200-300 $\mu$ l of benzene containing $\cong 10^{6} \mathrm{dpm}$ of $\left[{ }^{14} \mathrm{C}\right]$ - or $\left[{ }^{3} \mathrm{H}\right]$ cholesterol. The benzene was evaporated by a stream of $\mathrm{N}_{2}$ and the presence of the cholesterol label in mixed micelles was confirmed by gel chromatography (vide infra). Labeling of bile with $\left[{ }^{14} \mathrm{C}\right]-$ lecithin was performed in a similar manner. Test solutes, BSP, cBSP, ICG, BR, rose bengal, Evans blue, phenol red, urea, erythritol, and sucrose were dissolved in bile in vitro before ultrafiltration and ultracentrifugation in most studies. For comparison, ultrafiltration and ultracentrifugation of bile collected from rats that had been infused intravenously with BSP, ICG, or rose bengal was also performed. In contrast, cBR, iopanoic acid, $\left[{ }^{3} \mathrm{H}\right]$ diphenylhydantoin, $\left[{ }^{3} \mathrm{H}\right]$ testosterone, and $\left[{ }^{3} \mathrm{H}\right]$ diethylstilbesterol were not added to bile in vitro; rather in all experiments bile was collected from rats infused intravenously with BR, iopanoic acid, or the labeled drugs, respectively. No attempt was made to identify the 
biliary metabolites of iopanoic acid, diphenylhydantoin, testosterone, or diethylstilbesterol.

Gel chromatography. A K9-30 column (Pharmacia Fine Chemicals, Piscataway, N. J.) containing $\cong 18 \mathrm{ml}$ of G-100 Sephadex (Pharmacia Fine Chemicals) was preequilibrated with 3-column vol of $60 \mathrm{mM}$ taurocholate dissolved in S. The column was overlayered with $0.5 \mathrm{ml}$ of bile containing $\left[{ }^{3} \mathrm{H}\right]-$ or $\left[{ }^{14} \mathrm{C}\right]$ cholesterol-labeled mixed micelles (CLMM) or $\left[{ }^{14} \mathrm{C}\right]$ lecithin-labeled micelles and then eluted with $60 \mathrm{mM}$ taurocholate in S. The eluate was collected in 1-ml fractions and analyzed for radioactivity, bile salt, cholesterol, and phospholipid. This relatively high concentration of taurocholate in $\mathrm{S}$ was used for column preequilibration and elution (as well as subsequent ultracentrifugation studies) because preliminary experiments with lower concentrations (3-10 $\mathrm{mM}$ ) did not result in co-filtration of cholesterol, phospholipid, and bile salt. Instead, cholesterol and phospholipid appeared in the void volume determined with Blue Dextran (Pharmacia Fine Chemicals) and the bile salt peak coincided with the total column volume. This presumably reflected dissolution of the mixed micelles with microprecipitation of the cholesterol and phospholipid. Concentrations of taurocholate ranging from 40 to $60 \mathrm{mM}$ gave similar results.

Ultrafiltration studies. Before ultrafiltration, bile was passed through a coarse filter (1.2- $\mu \mathrm{m}$ Millipore filter, Millipore Corp., Bedford, Mass.) that removed mucus and particulate debris but not CLMM (recovery of CLMM was $100 \%$ ). Ultrafiltration of bile or other solutions was performed with an Amicon multi-micro UF system (Amicon Corp., Lexington, Mass.) in a $\mathrm{N}_{2}$ atmosphere at 40 pounds/in ${ }^{2}$. Bile and other solutions were adjusted to $\mathrm{pH} 7.6-8.0$ with $0.01 \mathrm{~N} \mathrm{HCl}$ before study and were stirred continuously so that the vortex did not exceed one-third of the solution height. Filtration was terminated when one-fourth to one-half of the original 3-5 ml remained in the cell. Because the critical micellar concentration of bile salts is relatively independent of temperature between 20 and $40^{\circ} \mathrm{C}(36)$, all studies were performed at room temperature.

The retention of test solute by a particular membrane was determined by calculating the "rejection coefficient" (r). $r$ represents the fraction of test solute in a given volume of filtered solution that does not pass through the membrane, that is, is rejected by the membrane. $\mathrm{r}$ can be calculated based on measurement of solute concentration in the retentate $\left(C_{R}\right)$ and filtrate $\left(C_{F}\right)$ by the formula $r=1-C_{F} / C_{R}$, or it can be calculated from measurements of retentate concentration alone by the formula derived below.

Amicon ultrafiltration membranes (Amicon Corp.) have a thin upper ultrafiltration "skin" which discriminates molecules with respect to size. This is supported by a nondiscriminatory and much thicker supporting matrix (37). This porous matrix may adsorb molecules passing the upper filtering surface, as indicated by the fact that recovery of filtered bile salts and organic anions was generally incomplete and unpredictable. After use with substances such as bilirubin or ICG, the supporting matrix (but not the upper skin) was densely colored by adsorbed dye, and the percent recovery was not improved by presoaking the membrane in test solute or by increasing test solute concentration. Because of this adsorption of solute to the matrix, calculations based on ultrafiltrate analysis would tend to spuriously overestimate $r$ (38). This potential source of error was avoided with the formula derived below for calculation of $\mathrm{r}$ based on retentate analysis, ${ }^{2}$ in which $V$ equals retentate volume at any time, $t$, and $Q_{F}$

${ }^{2}$ Derivation provided by Amicon Scientific Systems Division, Lexington, Mass. equals ultrafiltration flow rate. As discussed above, rejection coefficient can be calculated by the formula $\mathrm{r}=1-\mathrm{C}_{\mathrm{F}} /$ $C_{R}$. Thus, $C_{F}=C_{R}(1-r)$. Conservation of mass requires that $d V / d t=-\mathrm{Q}_{\mathrm{F}}, \quad d V=-\mathrm{Q}_{\mathrm{F}} d t \quad$ and $\quad d\left(V \mathrm{C}_{\mathrm{R}}\right) / d t=-\mathrm{Q}_{\mathrm{F}} \mathrm{C}_{\mathrm{F}}$ $=-\mathrm{Q}_{\mathrm{F}} \mathrm{C}_{\mathrm{R}}(1-\mathrm{r})$. Rearranging, $\quad d V \mathrm{C}_{\mathrm{R}}=V d \mathrm{C}_{\mathrm{R}}+\mathrm{C}_{\mathrm{R}} d V$ $=-\mathrm{Q}_{\mathrm{F}} \mathrm{C}_{\mathrm{R}}(1-\mathrm{r}) d t=\mathrm{C}_{\mathrm{R}}(1-\mathrm{r}) d V$ and $V d \mathrm{C}_{\mathrm{R}}=-\mathrm{rC}_{\mathrm{R}} d V$ Thus, $d \mathrm{C}_{\mathrm{R}} / \mathrm{C}_{\mathrm{R}}=\mathrm{r} d V / V$.

Integrating from zero time, when $\mathrm{C}_{\mathrm{R}}=\mathrm{C}_{0}$ (original solute concentration before ultrafiltration) and $V=V_{0}$ (volume above the membrane before ultrafiltration) to time $t$, when $C_{R}=C_{f}$ (final concentration of solute in retentate) and $V=V_{f}$ (final retentate volume) yields the following expression for $r(38,39)$ : $r=\ln \left(C_{f} / C_{o}\right) / \ln \left(V_{o} / V_{f}\right)$. Calculation of $r$ is thus based on retentate analysis alone and is not affected by adsorption of solute to the supporting matrix. To the extent that adsorption to the thin ultrafiltration skin had occurred, this would have decreased rather than increased $r$ and thus reduced apparent micellar association $\left(\mathrm{R}^{\prime}\right)$ as defined below.

We have expressed $\mathrm{r}$ in the more convenient form of a percentage where $R$ (percent retention) $=r \times 100$. Before the ultrafiltration studies membranes were rinsed by filtering several cell volumes of distilled water through the membrane. Because dye dilution studies indicated that an average of 0.14 $\mathrm{ml}$ of fluid remained in the cell after the preliminary rinse with distilled water and after aspiration of the retentate, 0.14 $\mathrm{ml}$ was added to both the $V_{\mathrm{o}}$ and $V_{\mathrm{f}}$ terms in the calculation of $\mathrm{r}$.

In preliminary experiments several membranes with different compositions and mol wt cutoffs $(2,000-20,000$ daltons) were tested (UM2, DM5, UM10, PM10, UM20, Amicon Corp.). $R$ for CLMM ( $\left.R_{\text {CLMM }}\right)$ averaged $93 \%$ or greater for each of these membranes. DM5 and PM 10 were selected for the definitive experiments because they showed the least intermembrane variation in retention of test solutes, and in contrast to the UM membranes which have some free ionic sites, they have an uncharged, covalently cross-linked surface that is less likely to interact with organic anions and other charged bile constituents (37). This latter point may explain the unexpectedly high $\mathbf{R}_{\text {CLMM }}$ shown by the UM20 (20,000 mol wt) membrane. PM10 membranes have the additional property of very rapid filtration which is a particular advantage when working with labile compounds such as $\mathrm{cBR}$ and BR. Properties of the DM5 and PM10 membranes used are summarized in Table I.

Because all test solutes dissolved in $\mathrm{S}$ freely penetrated the PM 10 membrane (mean $R_{S}=1.8 \%$ ), the increased retention of test solutes dissolved in bile presumably reflects association of test solutes with larger, nonpermeating ag-

TABLE I

Membrane Filtration Properties

\begin{tabular}{lcc}
\hline & DM5 & PM10 \\
\hline $\begin{array}{l}\text { Mol wt cutoff for globular proteins } \\
\text { Filtration rate for deionized water, }\end{array}$ & 5,000 & $16,000^{*}$ \\
$\quad \mathrm{ml} / \mathrm{cm}^{2} / \mathrm{min}$ & $0.04-0.1$ & $1-4$ \\
$\begin{array}{l}\text { Mean R of CLMM during bile } \\
\quad \text { filtration, mean } \pm \text { SE }\end{array}$ & $100 \pm 4.5$ & $93.0 \pm 0.03$ \\
$\begin{array}{l}\text { Mean R of bile salts during bile } \\
\quad \text { filtration, mean } \pm \text { SE }\end{array}$ & $100 \pm 7.0$ & $40.0 \pm 4.02$ \\
\hline
\end{tabular}

* Although listed in Amicon brochures as 10,000, information obtained from the Amicon Scientific System Division and Amicon publication no. 427 indicates that the molecular weight cutoff for globular proteins of the PM10 membrane is $\cong 16,000$. 


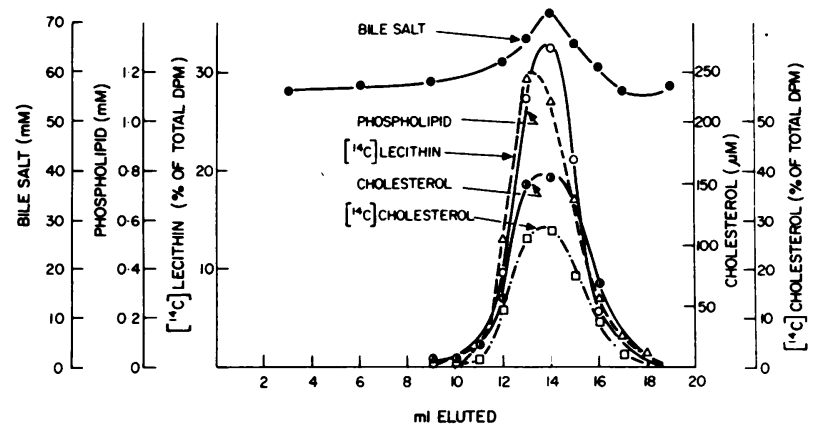

Figure 1 Gel chromatography of bile. Bile containing $\left[{ }^{14} \mathrm{C}\right]$ cholesterol- or $\left[{ }^{14} \mathrm{C}\right]$ lecithin-mixed micelles was applied to a G-100 Sephadex column that had been preequilibrated and was subsequently eluted with $60 \mathrm{mM}$ taurocholate dissolved in a bile electrolyte solution. The labeled cholesterol and lecithin co-chromatographed with unlabeled cholesterol, phospholipid, and bile salt, indicating the presence of label exclusively in the mixed micellar fraction.

gregates, that is, mixed micelles. In bile ultrafiltration studies, therefore, $R_{S}$ was divided by $R_{\text {CLMM }}$ to calculate a "relative retention" $\left(\mathbf{R}^{\prime}\right)$ for each solute: $\mathbf{R}^{\prime}=\left(\mathbf{R}_{S} / \mathbf{R}_{\text {CLM }}\right) \times 100$.

Assuming that test solute dissolved in bile does not penetrate the membrane as a result of its association with mixed micelles, $R^{\prime}$ can be taken as a direct measure of the extent to which each test solute is associated with mixed micelles. Determination of $R^{\prime}$ rather than simply $R_{S}$ corrects for possible errors caused by the measurement of small postfiltration sample volumes (because the $V_{0}$ and $V_{f}$ terms cancel) and also for minor intermembrane variability in $\mathbf{R}_{\text {CLMM }}$. $\mathbf{R}^{\prime}$ calculated in this way was unaffected by the concentration of test solute and by $V_{0} / V_{f}$ and showed an average coefficient of variation of $13.0 \%$.
Ultracentrifugation. Sucrose was dissolved in $60 \mathrm{mM}$ taurocholate in $S$ and a $10 \rightarrow 40 \%$ (wt/wt) continuous gradient was prepared in $5-\mathrm{ml}(1 / 2 \times 2$ inches $)$ cellulose nitrate tubes (Beckman Instruments, Inc., Spinco Div., Palo Alto, Calif.). This gradient was overlayered with $0.2 \mathrm{ml}$ of bile containing CLMM and(or) test solute and spun at $48,000 \mathrm{rpm}$ and $23^{\circ} \mathrm{C}$ in an SW-50L rotor (Beckman Instruments, Inc.). After ultracentrifugation for $50 \mathrm{~h}$ (except in preliminary experiments in which both shorter and longer spinning times were employed) the bottom of the tube was pierced and 20-drop fractions were collected for measurement of radioactivity and test solute concentration.

\section{RESULTS}

Bile composition and labeling of mixed micelles. Analysis of the homogeneous 2-liter pool of rat bile revealed the following bile salt and lipid composition: total bile salt concentration $=40 \mathrm{mM}(78 \%$ taurocholate, $12 \%$ glycocholate, and $10 \%$ taurodeoxycholate, taurochenodeoxycholate, and free cholate), phospholipid concentration $=4.2 \mathrm{mM}$, and cholesterol concentration $=0.435 \mathrm{mM}$. Gel chromatography of aliquots of this bile pool after $\left[{ }^{14} \mathrm{C}\right]$ cholesterol labeling (Fig. 1) demonstrated co-filtration of labeled cholesterol with unlabeled cholesterol, unlabeled phospholipid, labeled lecithin, and bile salt. Thus, labeled cholesterol was present exclusively in the mixed micellar fraction.

Ultrafiltration studies. The results of bile ultrafiltration studies are summarized in Table II. The findings with PM10 membranes indicated that each of the test solutes, ICG, iopanoic acid, Evans blue, rose bengal, BSP, cBR, BR, cBSP, and phenol red showed

TABLE II

Ultrafiltration of Bile Containing CLMM and Test Solute

\begin{tabular}{|c|c|c|c|c|c|c|c|c|}
\hline \multirow[b]{3}{*}{ Test solute } & \multicolumn{4}{|c|}{ PMIO } & \multicolumn{4}{|c|}{ DM5 } \\
\hline & \multirow{2}{*}{$\begin{array}{l}\text { No. of } \\
\text { studies }\end{array}$} & \multirow{2}{*}{$\begin{array}{c}\text { Initial } \\
\text { concentration } \\
\text { in bile (range) }\end{array}$} & \multicolumn{2}{|c|}{$\mathbf{R}^{\prime *}$} & \multirow{2}{*}{$\begin{array}{l}\text { No. of } \\
\text { studies }\end{array}$} & \multirow{2}{*}{$\begin{array}{c}\text { Initial } \\
\text { concentration } \\
\text { in bile }\end{array}$} & \multicolumn{2}{|c|}{$\mathbf{R}$} \\
\hline & & & Mean & SE & & & Mean & SE \\
\hline & & $m M$ & & & & $m M$ & & \\
\hline ICG & 15 & $0.12 \rightarrow 10.8$ & 93.3 & 2.05 & 3 & 0.80 & 100 & 1.33 \\
\hline Iopanoic acid metabolites & 4 & $2.20 \rightarrow 2.50$ & 86.0 & 2.27 & 4 & 1.6 & 100 & 14.7 \\
\hline Evans blue & 24 & $0.24 \rightarrow 17.4$ & 79.2 & 2.03 & 3 & 0.17 & 100 & 21.2 \\
\hline Rose bengal & 11 & $0.54 \rightarrow 10.3$ & 79.0 & 4.45 & 3 & 0.50 & 100 & 1.3 \\
\hline BSP & 23 & $0.36 \rightarrow 22.7$ & 74.7 & 2.43 & 3 & 0.40 & 96.0 & 0.86 \\
\hline cBR & 13 & $0.14 \rightarrow 7.7$ & 66.2 & 2.85 & 4 & 0.28 & 95.5 & 4.7 \\
\hline BR & 12 & $0.15 \rightarrow 0.56$ & 61.2 & 3.46 & 8 & 0.15 & 68.3 & 3.8 \\
\hline$\left[{ }^{3} \mathrm{H}\right]$ Diethylstilbesterol metabolites & 4 & trace & 43.6 & 2.90 & 2 & trace & 100 & - \\
\hline cBSP & 14 & $0.04 \rightarrow 16.4$ & 27.2 & 3.25 & 3 & 0.3 & 100 & 3.13 \\
\hline Phenol red & 12 & $1.5 \rightarrow 19.6$ & 26.0 & 3.52 & 3 & 1.5 & 100 & 6.0 \\
\hline$\left[{ }^{3} \mathrm{H}\right]$ Testosterone metabolites & 4 & trace & 10.4 & 3.2 & 2 & trace & 60.4 & - \\
\hline$\left[{ }^{3} \mathrm{H}\right]$ Diphenylhydantoin metabolites & 4 & trace & 2.2 & 0.94 & 2 & trace & 61.3 & - \\
\hline Sucrose & 3 & $3.0 \rightarrow 9.1$ & -1.5 & 1.5 & 2 & trace & 11.8 & - \\
\hline Erythritol & 4 & $3.8 \rightarrow 14.4$ & -2.6 & 2.5 & 2 & trace & 26.0 & - \\
\hline Urea & 5 & $0.6 \rightarrow 6.0$ & -4.3 & 2.1 & 2 & trace & 29.2 & - \\
\hline
\end{tabular}

${ }^{*} \mathrm{R}^{\prime},([\mathrm{R}$ of test solute $] /[\mathrm{R}$ of $\mathrm{CLMM}]) \times 100$. 


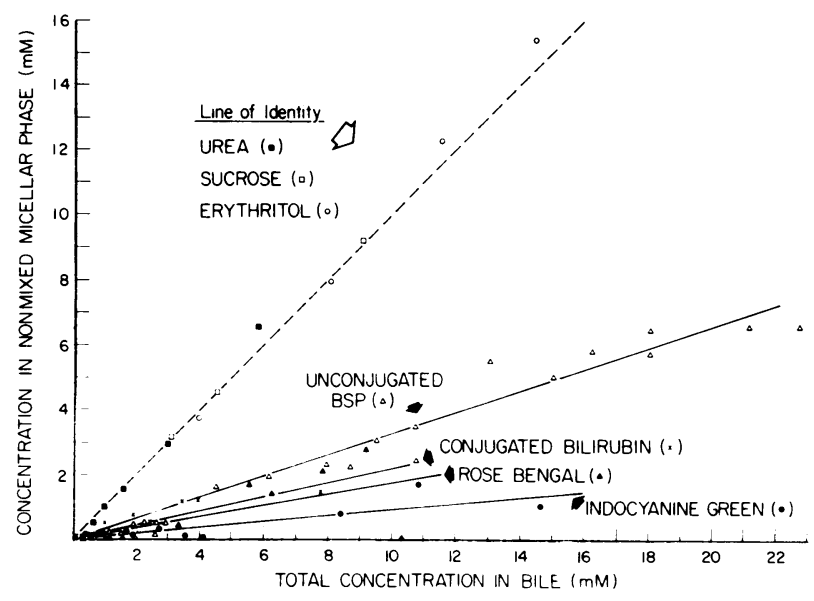

FIGURE 2 Ultrafiltration of bile containing labeled mixed micelles (CLMM) and selected test solutes. $\mathbf{R}^{\prime}$ ([retention of test solute/retention of CLMM] $\times 100$ ) was determined for each test solute, and the calculated concentration of each test solute in the nonmixed micellar phase, $\left(\left[100-R^{\prime}\right] / 100\right) \times$ total initial concentration in bile, was plotted vs. total initial bile concentration. Sucrose, urea, and erythritol, which show no association with CLMM, all fell on or above the line of identity. The remaining test solutes, all of which are concentrated in bile, did show an association with CLMM and fell well below the line of identity.

association with CLMM, that is, $\mathrm{R}^{\prime}$ for each of these test solutes in bile greatly $(P<0.001)$ exceeded $\mathrm{R}$ for the same test solute dissolved in $\mathrm{S}$. The percentage association of these substances with CLMM in bile $\left(\mathbf{R}^{\prime}\right)$ varied from 26 to $93 \%$. Each of these test substances (except Evans blue and BR) are also excreted in bile in high concentration relative to plasma. In contrast, sucrose, urea, and erythritol, which are not concentrated in bile relative to plasma (40), showed no association with CLMM during PM10 ultrafiltration. The results of PM10 ultrafiltration of bile samples containing ICG, rose bengal, $\mathrm{BSP}$, or cBSP which was prepared by infus- ing animals in vivo (average $R^{\prime}$ values: $I C G=89.9 \%$; rose bengal $=77.0 \% ; \quad \mathrm{BSP}=69.3 \% ; \quad \mathrm{cBSP}=23.0 \%$ ) were virtually identical with those using bile to which the test solute had been added in vitro (Table II). Because bile prepared by infusing the rats with BSP contained both BSP and cBSP, the concentration of BSP and $\mathrm{cBSP}$ in bile was determined individually before and after filtration, and $\mathrm{R}^{\prime}$ was calculated separately for each. The findings summarized in Table II also suggested an association between the labeled biliary metabolites of diethylstilbesterol and CLMM, whereas diphenylhydantoin and testosterone metabolites showed little or no association. These results are illustrated graphically in Fig. 2 in which the concentration of selected solutes in the nonmicellar phase of bile $\left(\left[100-R^{\prime}\right] \times\right.$ total bile conc/100) is plotted vs. total bile concentration. Whereas the values for sucrose, urea, and erythritol fall on or above the line of identity, those for ICG, rose bengal, Evans blue, cBR, and BSP all fall distinctly below this line. The concentration of these latter substances in the nonmicellar or aqueous phase of bile represents thus only a relatively small fraction of their total concentration in bile. Also illustrated in Fig. 2 is the fact that no distinct "micellar saturation point" was detectable for any of these substances over the concentration range studied. That is, partition between the micellar and nonmicellar phases did not show a distinct change even at solute concentrations in excess of those achievable in vivo by intravenous infusion of these substances.

Results of DM5 ultrafiltration of bile containing test solute and CLMM are summarized in Table II. With the exception of BR, each of the test solutes that had shown an association with CLMM during PM10 ultrafiltration (ICG, iopanoic acid, Evans blue, rose bengal, BSP, cBR, $\left[{ }^{3} \mathrm{H}\right]$ diethylstilbesterol metabolites, cBSP, and phenol red) was almost entirely present in bile (range $=95-100 \%)$ in the form of macromolecular complexes

TABLE III

DM5 Membrane Retention of Test Solutes Dissolved in Various Solutions

\begin{tabular}{lccccccc}
\hline & \multicolumn{7}{c}{ Solution in which test solute dissolved } \\
\cline { 2 - 8 } \multicolumn{1}{c}{ Test solute } & $\begin{array}{c}\text { Distilled } \\
\text { water }\end{array}$ & $\begin{array}{c}\mathrm{NaCl} \\
(0.1 \mathrm{M})\end{array}$ & $\begin{array}{c}\mathrm{NaCl} \\
(5.0 \mathrm{M})\end{array}$ & $\begin{array}{c}\text { Urea } \\
(5 \mathrm{M})\end{array}$ & $\begin{array}{c}\text { Tris } \\
(\mathrm{pH} 7.2)\end{array}$ & $\begin{array}{c}\text { Tris } \\
(\mathrm{pH} 9.0)\end{array}$ & $\mathrm{s}$ \\
\hline ICG & 100 & 42.8 & 0 & 90.7 & 31.3 & 47.0 & 62.0 \\
Evans blue & 77.8 & 56.2 & 10.9 & 100 & 62.4 & 81.6 & 88.7 \\
Rose bengal & 84 & 15 & 0 & 89.3 & 62.5 & 68.5 & 55 \\
BSP & 90.4 & 36.8 & 0 & 73.2 & 65.9 & 84.6 & 67.2 \\
cBR & 73.8 & 36.4 & 29.0 & 75.6 & 57.2 & 97.2 & 100 \\
BR & $99.6 \pm$ & 96.1 & 22.0 & 89.2 & 70.8 & 80.4 & 86.8 \\
cBSP & 78.4 & 81.8 & 32.0 & 97.8 & 82.5 & 83.0 & 76.7 \\
Phenol red & 100 & 73.4 & 0 & 81.4 & 85.2 & 85.4 & 66.2 \\
\hline
\end{tabular}

* Concentration of test solutes varied from 0.001 to $10 \mathrm{mM}$.

\$ $\mathrm{BR}$ was dissolved in a dilute $\mathrm{NaCl}(2 \mathrm{mM}) / \mathrm{Na}_{2} \mathrm{CO}_{3}(1 \mathrm{mM})$ solution rather than distilled water. 
too large to pass this 5,000-mol wt cutoff membrane. By comparison, DM5 retention of sucrose, urea, and erythritol was very much smaller (11.8-29.2\%). The cause and significance of the residual retention of these three compounds are unclear.

Test solutes that had shown a significant association with CLMM during PM10 bile ultrafiltration also were dissolved in various aqueous solutions and ultrafiltered through the DM5 membranes (Table III). Membrane retention of these substances dissolved in distilled water (or very low $\left[\mathrm{NaCl}=2 \mathrm{mM}, \mathrm{Na}_{2} \mathrm{CO}_{3}=1 \mathrm{mM}\right.$ ] ionic strength solution in the case of $\mathrm{BR}$ ) ranged from $73.8-100 \%$, suggesting formation of self-aggregates too large to pass the membrane. $R$ was independent of dye concentration over the range studied (0.001-10 $\mathrm{mM})$. The strikingly different retention properties of the PM10 (Table I) and DM5 (Table III) membranes for the test solutes dissolved in $S$ (mean $R$ values were 1.8 and $75.3 \%$, respectively) suggested that these self-aggregates in $\mathrm{S}$ have mol wt between 5,000 and 16,000 . When test solutes were dissolved in solutions of increasing ionic strength $(\mathrm{NaCl}=0.1-5.0 \mathrm{M})$, a progressive decrease in $\mathrm{R}$ was observed for each test solute during DM5 ultrafiltration (mean $\mathrm{R}$ values for distilled water and $5 \mathrm{M} \mathrm{NaCl}$ were 88.0 and $11.7 \%$, respectively [Table III]). In contrast, dissolving test solutes in $5 \mathrm{M}$ urea did not reduce $R$ and raising the $\mathrm{pH}$ from 7.2 to 9.0 (exceeding the physiologic range of bile) increased $\mathrm{R}$ only slightly (except for $\mathrm{cBR}$ ). These results suggest that each of these substances forms selfaggregates stabilized primarily by ionic, rather than hydrophobic or hydrogen, bonds.

Ultracentrifugation. In preliminary studies, bile containing CLMM and a high concentration of $\mathrm{cBR}$ was ultracentrifuged for periods ranging from 3 to $120 \mathrm{~h}$. As illustrated in Fig. 3, the location of the pigment peak determined visually (by measuring its distance from the bottom of the tube) coincided at all times with the CLMM peak determined by scintillation counting of tube fractions. On the basis of these experiments, $50 \mathrm{~h}$ of centrifugation was chosen for the subsequent studies because it was the shortest time that produced a distinct micellar band clearly separated from the bottom and top of the gradient. The profile of a gradient containing bile with labeled CLMM after $50 \mathrm{~h}$ of centrifugation is shown in Fig. 4. The sucrose concentration $(\mathrm{wt} / \mathrm{wt})$ decreased curvilinearly from 40 to $10 \%$, the CLMM formed a distinct peak, and total bile salt concentration at all points in the gradient greatly exceeded the critical micellar concentration for taurocholate.

Ultracentrifugation profiles of bile containing various test solutes and CLMM are illustrated in Fig. 5. Each of the substances that had shown a strong association ( $\mathrm{R}^{\prime}>40 \%$ ) with CLMM by PM10 ultrafiltration also sedimented with CLMM. Because these test solutes

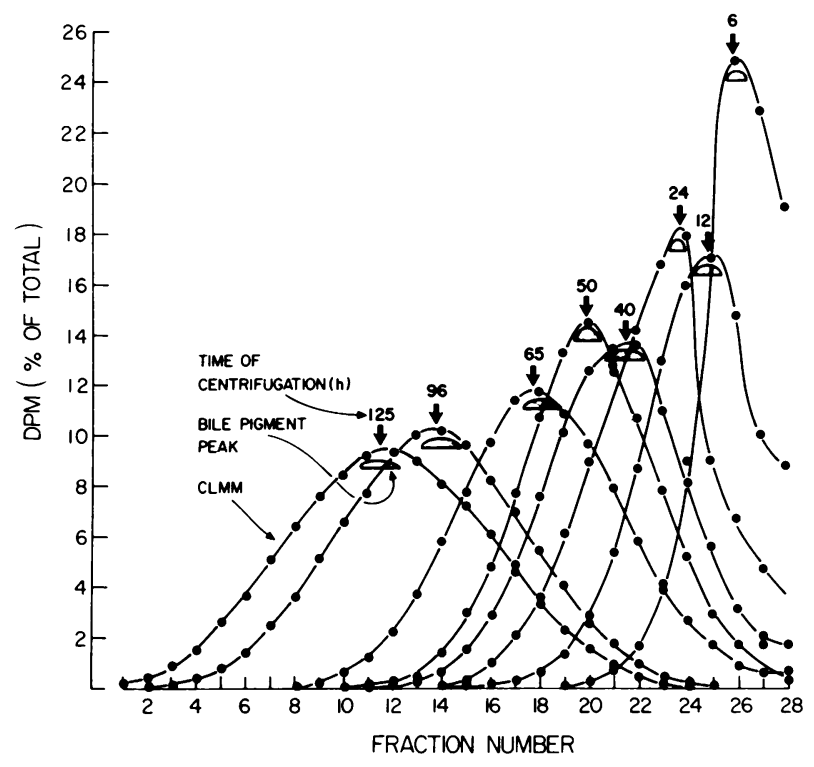

FIGURE 3 Ultracentrifugation of bile containing labeled mixed micelles (CLMM). Note that the bile pigment peak determined visually and the CLMM peak determined by scintillation counting of tube fractions coincided at all spinning times from 6 to $125 \mathrm{~h}$.

sedimented with CLMM through a medium containing taurocholate micelles, these findings suggest that these test substances have a greater affinity for mixed micelles than for pure bile salt micelles. Substances such as phenol red, which had exhibited a weaker association with CLMM by ultrafiltration, showed an intermediate pattern with only a portion of the test solute sedimenting with CLMM. Sucrose, erythritol, and urea, which had failed to exhibit any association with micelles by ultrafiltration, also showed none by ultracentrifugation. Thus the two independent techniques of ultrafiltration and ultracentrifugation gave qualitatively similar answers to the question of whether, and

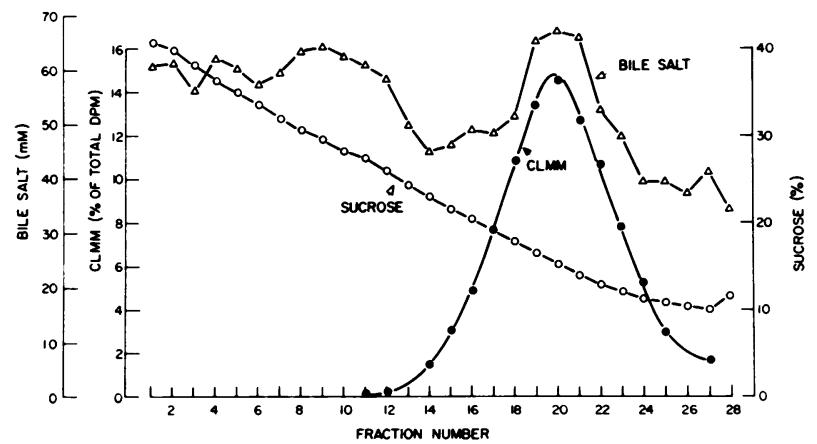

FIGURE 4 Ultracentrifugation profile of bile. Bile containing labeled mixed micelles was layered over a $10 \rightarrow 40 \%$ continuous sucrose gradient (prepared by dissolving the sucrose in $60 \mathrm{mM}$ taurocholate solution with an electrolyte composition similar to bile) and centrifuged at $23^{\circ} \mathrm{C}$ and $48,000 \mathrm{rpm}$ for $50 \mathrm{~h}$. 


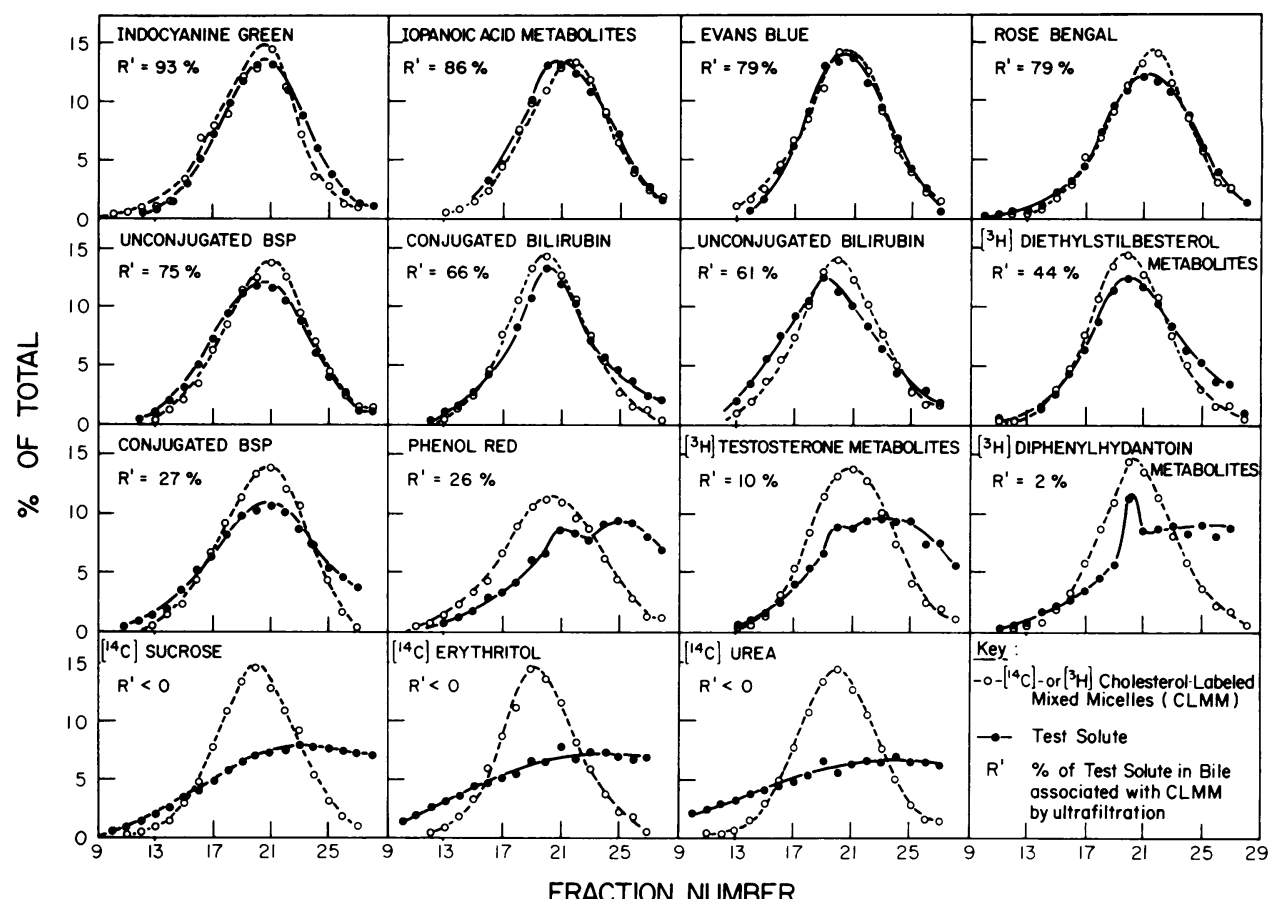

FIGURE 5 Ultracentrifugation of bile containing CLMM and test solute. Substances that showed a strong association with CLMM by ultrafiltration $\left(\mathrm{R}^{\prime}>40 \%\right)$ sedimented with CLMM, whereas substances that showed no association with CLMM by ultrafiltration $\left(\mathbf{R}^{\prime}<0 \%\right)$ also showed none during ultracentrifugation. Substances that showed a weak association with CLMM by ultrafiltration $\left(40 \%>\mathrm{R}^{\prime}>0 \%\right)$ had an intermediate pattern on ultracentrifugation.

to what extent, each test solute was associated with CLMM. Ultracentrifugation studies of bile samples containing ICG, rose bengal, BSP, or cBSP which had been prepared by infusing the animals in vivo, gave results analogous to those in Fig. 5, obtained with test solutes that had been added in vitro.

Results of control ultracentrifugation studies in which test solutes were dissolved in $\mathrm{S}$ rather than in bile gave results very different from those shown in Fig. 5 . Whereas test solutes dissolved in bile had shown a relatively uniform centrifugation pattern (Fig. 5), no such uniformity was observed in S. Some test solutes (ICG, BSP, and rose bengal) actually sedimented more rapidly in the absence of mixed micelles, and in all instances the solute peak was lower and less well defined. Inulin (mol wt, 5,000 ) has been shown to exhibit little sedimentation under experimental conditions similar to those employed in the present experiments (18). It is likely, therefore, that the comparatively rapid sedimentation in $\mathrm{S}$ of our test solutes, all of which are in the $300-1,200-\mathrm{mol} w t$ range, reflects their tendency to self-aggregate. BSP sedimented more rapidly than cBSP as has been observed previously (18).

\section{DISCUSSION}

We have investigated the interaction between $\left[{ }^{3} \mathrm{H}\right]-$ or $\left[{ }^{14} \mathrm{C}\right]$ cholesterol-labeled mixed micelles and a variety of test solutes by ultrafiltration and ultracentrifugation. Our findings indicate that the substances excreted in bile at high concentration relative to plasma (BSP, cBSP, cBR, ICG, rose bengal, and iopanoic acid) (1-6) (Unpublished observations.) are physically associated with CLMM ( $\left.\mathbf{R}^{\prime}=27-93 \%\right)$. Included among this group were those organic anions (BSP, cBSP, ICG, and cBR) for which biliary secretion has been shown to rise in response to increasing biliary output of bile salts and mixed micelles $(9,12-15)$. In contrast, sucrose, urea, and erythritol, which are excreted in bile at concentrations equal to or less than those in plasma (40), were found not to be associated with CLMM by ultrafiltration or ultracentrifugation.

In addition to their association with mixed micelles, ICG, Evans blue, rose bengal, BSP, cBSP, BR, cBR, and phenol red in aqueous solution form self-aggregates which do not pass a 5,000-mol wt membrane. Because self-aggregation occurred even at very low concentrations, it is possible that these dyes in aqueous solution form polydisperse aggregates rather than true micelles, The fact that $5 \mathrm{M} \mathrm{NaCl}$, but not $5 \mathrm{M}$ urea, disrupted these aggregates also suggests that ionic rather than hydrogen or hydrophobic bonds are involved in their formation. Although the present studies provide no direct evidence that self-association of these dyes occurs in native bile, aggregates were identifiable in an 
artificial bile electrolyte solution. Moreover, retention of some of these dyes (cBSP, phenol red [Table II]) in bile was strikingly higher by the 5,000- than the $16,000-\mathrm{mol}$ wt membrane whereas retention of mixed micelles did not differ appreciably between the two membranes. This suggests that in native bile these dyes in part may exist in the form of macromolecular complexes that are smaller than mixed micelles.

These findings have two major physiologic implications. The first relates to the reported observation that the maximum biliary secretion rate for BSP, $c B S P, c B R$, and ICG is increased by bile salt infusion $(9,12-15)$. Whereas it is easy to understand the link between biliary output of bile salts and hydrophobic substances such as cholesterol and phospholipids (41), which are excreted almost exclusively as part of the mixed micellar complex, the relationship between bile salt output and the excretion of hydrophilic organic anions is less readily apparent.

One possible explanation would be a linkage of some sort between the excretion of bile salts and organic anions $(14-16,42)$. Although the observation that Corriedale sheep excrete taurocholate normally $(43,44)$ has been taken as evidence that bile salts and organic anions are excreted via functionally separate pathways, this interpretation remains tentative (42), because the effect of BSP infusion on taurocholate excretion has not been studied in these animals, and BSP has been reported to compete with bile salts for binding to isolated liver plasma membranes (45). Moreover, bile salt infusion has been found to alter the scanning electron microscopic appearance of canalicular membranes $(46,47)$, modify the lipid composition and enzymatic activity of liver plasma membrane preparations enriched in bile canaliculi (47), and alter the $K_{\mathrm{m}}$ for BSP excretion (24). These observations are in fact consistent with the hypothesis that bile salts might directly alter membrane transport of organic anions.

The present findings suggest an alternative explanation, namely, that physical interaction between organic anions and biliary mixed micelles accounts for the direct relationship between the excretion rate of bile salts and organic anions. Such an association would reduce the effective concentration of these organic anions in canalicular bile, thereby decreasing their availability for back diffusion across the canalicular membrane and increasing their net excretion (14-18, $23,25,42)$. Alternatively, if mixed micelles were formed within the hepatocytes and excreted intact, physical association between organic anions and mixed micelles would actually increase the unidirectional efflux rate of organic anions. Although the functional importance of micellar sequestration for the biliary excretion of organic anions has yet to be established, this general hypothesis is supported by previous studies of normal bile or synthetic solutions which indicated a physical association between BSP and taurocholate (18) and between bilirubin and mixed micelles or some other macromolecular complex in bile (19-22). The present findings extend these earlier observations and provide quantitative information on the physical association between several organic anions and mixed micelles. The reported observation that bile salt infusion produces a disproportionately greater increase in biliary output of BSP than of cBSP $(12,13)$ is thus entirely consistent with the present finding that association with CLMM $\left(\mathbf{R}^{\prime}\right)$ is greater for BSP than for cBSP (75 vs. $27 \%$, Table II).

Vonk and co-workers $(26,27)$ recently also have reported a physical association between solutes and mixed micelles, but have failed to demonstrate an increase in the biliary excretion rate for some of these solutes during taurocholate infusion. Interpretation of these findings is complicated by the fact that $T_{m}$ was not measured for these solutes and the ultracentrifugation technique employed fails to distinguish between association with mixed micelles and self-aggregatior. Other findings that might be considered as evidence against the present "micellar sink" hypothesis include the reported increase in BSP $T_{m}$ during infusion of dehydrocholate, a bile salt that does not form micelles, and the observation that fasting decreases bile salt output and BSP $T_{m}$, but does not affect the $T_{m}$ for rose bengal (48). The former observation might result from physical interaction between BSP and dehydrocholate, similar to that demonstrated for taurocholate (18). Because fasting produces complex alterations in hepatic function, the second observation is more difficult to interpret. Although these and other findings considered below illustrate the multiplicity of factors that may affect transport of organic anions from liver into bile, none of them refutes the potential importance of physical association with mixed micelles or other aggregates in the transport process.

Our findings also have important physiological implications regarding the nature of the hepatic secretory mechanism for organic anions. For example, it has long been recognized that the concentration of organic anions such as BR and BSP in bile may exceed their concentration in plasma by up to two orders of magnitude (1-6) and exceed their concentration in liver homogenate by 30 - to 50 -fold (4-6). Although measurements in whole liver homogenate ignore possible intracellular compartmentation (49), these findings have been taken as evidence that a steep concentration gradient exists across the canalicular membrane and that the secretory mechanism for organic anions is intrinsically concentrative, that is, active and energy requiring (7-11). However, physical association of these substances with mixed micelles and other aggregates serves to reduce their free concentration in bile. The present findings indicate that for each of the organic anions studied that are concentrated in bile relative to liver and(or) plasma, only a very small frac- 
tion $(0-5 \%)$ is present in bile in the form of monomer or small complexes. Whereas this does not exclude the existence of an electrochemical potential difference for these substances across the canalicular membrane, it suggests as an alternative possibility that the transport mechanism for these substances is equilibrative rather than intrinsically concentrative.

Although micellar transport and self-aggregation appear to be important factors in the concentrative transport of these organic solutes into bile, they clearly cannot be the sole determinants for their biliary excretion. Indeed, the concept of micellar transport is entirely consistent with the presence of carrier mechanisms within the canalicular or sinusoidal membrane $(45,50-53)$. This is illustrated by the finding with Evans blue, which is associated with CLMM and forms self-aggregates, yet is poorly transported into the hepatocyte and may therefore represent a compound for which no membrane carrier is available. It thus would appear that the substrate specificity of such carriers in the sinusoidal and(or) canalicular membrane may determine whether a given molecule is or is not transported into bile (54) whereas micellar association and self-aggregation may help explain the concentrative transport of those solutes for which an appropriate carrier is available.

\section{ACKNOWLEDGMENTS}

This work was supported in part by U. S. Public Health Service grants P50 AM-18520 and AM-11275, and 1 KO4 AM-00323 from the National Institutes of Health.

\section{REFERENCES}

1. Klaassen, C. D., R. J., Roberts, and G. L. Plaa. 1969. Maximal biliary excretion of bilirubin and sulfobromophthalein during various rates of infusion in rats of different weights and strains. Toxicol. Appl. Pharmacol. 15: $143-151$.

2. Paumgarten, G. 1975. The handling of indocyanine green by the liver. Schweiz. Med. Wochenschr. (Suppl.) 19-21.

3. Clarenberg, R., and C. C. Kao. 1973. Shared and separate pathways for biliary excretion of bilirubin and BSP in rats. Am. J. Physiol. 225: 192-200.

4. Billing, B. H., Q. Maggiore, and M. A. Cartter. 1963. Hepatic transport of bilirubin. Ann. N. Y. Acad. Sci. 111: 319-324.

5. Whelan, G., and B. Combes. 1971. Competition by unconjugated and conjugated sulfobromophthalein sodium (BSP) for a single excretory system.J. Lab. Clin. Med. 78: 230-244.

6. Bloomer, J. R., and J. Zaccaria. 1976. Effect of graded bilirubin loads on bilirubin transport by perfused rat liver. Am. J. Physiol. 230: 736-742.

7. Sperber, I. 1965. Biliary secretion of organic anions and its influence on bile flow. In The Biliary System. W. Taylor, editor. Blackwell Scientific Publications, Oxford. 457-467.

8. Sperber, I. 1959. Secretion of organic anions in the formation of urine and bile. Pharmacol. Rev. 11: 109-134.

9. O’Maille, E. R. L., T. G. Richards, and A. H. Short. 1966.
Factors determining the maximal rate of organic anion excretion by the liver and further evidence on the hepatic site of action of the hormone secretin. J. Physiol. (Lond.). 186: 424-438.

10. Goresky, C. A. 1965. The hepatic uptake and excretion of sulfobromophthalein and bilirubin. Can. Med. Assoc.J. 92: 851-857.

11. Fleischner, G., and I. M. Arias. 1970. Recent advances in bilirubin formation, transport, metabolism and excretion. Am. J. Med. 49: 576-589.

12. Barnhart, J., D. Ritt, A. Ware, and B. Combes. 1973. A Comparison of the effects of taurocholate and theophylline on BSP excretion in dogs. In The Liver. Quantitative Aspects of Structure and Function. S. Karger, Basel. 315-325.

13. Boyer, J. L., R. L. Scheig, and G. Klatskin. 1970. The effect of sodium taurocholate on the hepatic metabolism of sulfobromophthalein sodium (BSP). The role of bile flow. J. Clin. Invest. 49: 206-215.

14. Vonk, R. J., H.v. d. Veen, G. Prop, and D. K. Meijer. 1974. The influence of taurocholate and dehydrocholate choleresis on plasma disappearance and biliary excretion of indocyanine green in the rat. Naunyn-Schmiedebergs Arch. Pharmakol. 282: 401-410.

15. Goresky, C. A., H. H. Haddad, W. S. Kluger, B. E. Nadeau, and G. G. Bach. 1974. The enhancement of maximal bilirubin excretion with taurocholate-induced increments in bile flow. Can. J. Physiol. Pharmacol. 52: 389-403.

16. Gibson, G. E., and E. L. Forker. 1974. Canalicular bile flow and bromosulphthalein transport maximum: the effect of a bile salt-independent choleretic, SC-2644. Gastroenterology. 66: 1046-1053.

17. Bissell, D. M., D. R. Deal, and L. E. Hammaker. 1975. Determinants of bilirubin transport into bile. Gastroenterology. 69: 809. (Abstr.)

18. Ware, A. J., M. C. Carey, and B. Combes. 1976. Solution properties of sulfobromophthalein sodium (BSP) compounds alone and in association with sodium taurocholate (TC). J. Lab. Clin. Med. 87: 443-456.

19. Juniper, K. 1965. Physicochemical characteristics of bile and their relation to gallstone formation. Am. J. Med. 39: 98-107.

20. Vershure, J. C. M., and P. F. Mijnlieff. 1956. The dominating macromolecular complex of human gallbladder bile. Clin. Chim. Acta. 1: 154-166.

21. Bouchier, I. A. D., and S. R. Cooperband. 1967. Isolation and characterization of a macromolecular aggregate associated with bilirubin. Clin. Chim. Acta. 15: 291-302.

22. Nakayama, F. 1966. Nature of cholesterol-complexing macromolecular fractions in bile. Clin. Chim. Acta. 13: $212-220$.

23. Goresky, C. A. 1975. The hepatic uptake process: its implications for bilirubin transport. In Jaundice. C. A. Goresky and M. M. Fisher, editors. Plenum Publishing Corp., New York. 159-173.

24. Forker, E. L. 1977. Canalicular anion transport: effect of bile acids and bile acid independent choleretics. In Chemistry and Physiology of Bile Pigments. P. D. Berk, and N. I. Berlin, editors. U. S. Government Printing Office, Washington, D. C. 383-389.

25. Javitt, N. B. 1969. Bile salt regulation of hepatic excretory function. Gastroenterology. 56: 622-624.

26. Vonk, R. J., P. Jekel, and D. K. F. Meijer. 1975. Choleresis and hepatic transport mechanisms. II. Influence of bile salt choleresis and biliary micelle binding on biliary excretion of various organic anions. Naunyn-Schmiedebergs Arch. Pharmakol. 290: 375-387.

27. Vonk, R. J., A. B. D. van Doorn, A. H. J. Scaf, and D. K. F. 
Meijer. 1977. Choleresis and hepatic transport mechanisms. III. Binding of ouabain and K-strophanthoside to biliary micelles and influence of choleresis on their biliary excretion. Naunyn-Schmiedebergs Arch. Pharmakol. 300: 173-177.

28. Wolkoff, A. W., B. F. Scharschmidt, P. H. Plotz, and P. D. Berk. 1976. Purification of conjugated bilirubin: a new approach utilizing albumin-agarose gel affinity chromatography. Proc. Soc. Exp. Biol. Med. 152: 20-23.

29. Whelan, G., J. Hock, and B. Combes. 1970. A direct assessment of the importance of conjugation for biliary transport of sulfobromophthalein sodium. J. Lab. Clin. Med. 75: 542-557.

30. Malloy, H. T., and K. A. Evelyn. 1937. The determination of bilirubin with the photoelectric colorimeter. J. Biol. Chem. 119: 481-490.

31. Kaufman, L., F. Deconinck, D. C. Price, P. Guessy, C. J. Wilson, B. Hruska, S. J. Swann, D. C. Camp, A. L. Voegele, R. D. Friesen, and J. A. Nelson. 1976. An automated fluorescent excitation analysis system for medical applications. Invest. Radiol. 11: 210-215.

32. Talalay, P. 1960. Enzymatic analysis of steroid hormones. Methods Biochem. Anal. 8: 119-143.

33. Admirand, W. J., and D. M. Small. 1968. The physicochemical basis of cholesterol gallstone formation in man. J. Clin. Invest. 47: 1043-1052.

34. Hofmann, A. F. 1962. Thin-layer adsorption chromatography of free and conjugated bile acids on silicic acid. J. Lipid Res. 3: 127-128.

35. Bartlett, G. R. 1959. Phosphorus assay in column chromatography. J. Biol. Chem. 234: 466-468.

36. Carey, M. C., and D. M. Small. 1970. The characteristics of mixed micellar solutions with particular reference to bile. Am. J. Med. 49: 590-608.

37. Ultrafiltration membrane and equipment selection guide. 1975. Amicon Corp. publication no. 448A. Lexington, Mass.

38. Blatt, W. F. 1976. Principles and Practice of Ultrafiltration. In Membrane Separation Processes. P. Meares, editor. Elsevier Press, Amsterdam.

39. Applications manual: concentrating, desalting, and separating solutions and suspensions. 1975. Amicon Corp. publication no. 427. Lexington, Mass. 25.

40. Forker, E. L. 1968. Bile formation in guinea pigs: analysis with inert solutes of graded molecular radius. Am. J. Physiol. 215: 56-62.
41. Wagner, C. I., B. W. Trotman, and R. D. Soloway. 1976. Kinetic analysis of biliary lipid excretion in man and dog. J. Clin. Invest. 57: 473-477.

42. Forker, E. L. 1977. Mechanisms of hepatic bile formation. Annu. Rev. Physiol. 39: 323-347.

43. Arias, I. M. 1966. The excretion of conjugated bilirubin by the liver cell. Medicine (Baltimore). 45: 513-515.

44. Alpert, S., M. Mosher. A. Shanske, and I. M. Arias. 1969. Multiplicity of hepatic excretory mechanisms for organic anions. J. Gen. Physiol. 53: 238-247.

45. Accatino, L., and F. R. Simon. 1976. Identification and characterization of a bile acid receptor in isolated liver surface membranes. J. Clin. Invest. 57: 496-508.

46. Miyai, K., A. L. Richardson, W. Mayr, and N. B. Javitt. 1977. Subcellular pathology of rat liver in cholestasis and choleresis induced by bile salts. I. Effects of lithocholic, $3 \beta$-hydroxy-5-cholenic, cholic, and dehydrocholic acids. Lab. Invest. 36: 249-258.

47. Nemchausky, B. A., T. J. Layden, and J. L. Boyer. 1977. Effects of chronic cholestatic infusions of bile acids on the membrane of the bile canaliculus. Lab. Invest. 36: 259267.

48. Mahu, J.-L., P. Duvaldestin, D. Dhumeaux, and P. Berthelot. 1977. Biliary transport of cholephilic dyes: evidence for the two different pathways. Am. J. Physiol. 232: E445-450.

49. Kirshenbaum, G., D. M. Shames, and R. Schmid. 1976. An expanded model of bilirubin kinetics: effect of feeding, fasting, and phenobarbital in Gilbert's syndrome. J. Pharmacokinet. Biopharm. 4: 115-155.

50. Wolkoff, A. W., and I. M. Arias. 1977. ${ }^{35}$ S-BSP binding by purified rat liver cell plasma membrane subfractions. Gastroenterology. 73: A57/1255.

51. Reichen, J., and P. D. Berk. 1977. Isolation of an organic anionic dye (OAD) binding protein from rat liver plasma membrane (LPM). Gastroenterology. 73: A-44/1242.

52. Reichen, J., B. L. Blitzer, and P. D. Berk. 1977. The binding of organic anionic dyes to hepatocellular plasma membranes. Clin. Res. 25: 468A. (Abstr.)

53. Scharschmidt, B. F., J. G. Waggoner, and P. D. Berk. 1975. Hepatic organic anion uptake in the rat. J. Clin. Invest. 56: $1280-1292$.

54. Blanckaert, N., K. P. M. Heirwegh, and Z. Zaman. 1977. Comparison of the biliary excretion of the four isomers of bilirubin-IX in Wistar and homozygous Gunn rats. Biochem. J. 164: 229-236. 